$\xi=\Phi$

\title{
Effects of internalized stigma on symptoms and quality of life in schizophrenic patients; mediated by dysfunctional attitude
}

\author{
Sajida Shaheen *, Rizwana Amin \\ Department of Applied Psychology Bahauddin Zakariya University Multan, 60000 Pakistan \\ *Corresponding author E-mail: sajal80@yahoo.co.uk
}

\begin{abstract}
The objective of this study was to determine the effects of internalized stigma on symptoms, quality of life of schizophrenic patients; mediated by dysfunctional attitude. A descriptive correlational research design was used to investigate the relationship between symptoms, quality of life and dysfunctional attitude in schizophrenic patients. Linear regression was used to investigate the mediational effects of dysfunctional attitude. Purposive sampling technique was used for the selection of the participants. The study was conducted on diagnosed schizophrenic patients from psychiatry ward of Nishtar Hospital Multan, Fountain House Rehabilitation Centre Lahore and Punjab Institute of Mental Health Rehabilitation Centre Lahore. The sample of the study was 50 registered patients of schizophrenia. Calculated sample size was 50 schizophrenic patients among them 34 were Males and 16 were Females. Internalized Stigma of Mental Illness Scale was used to see the effects of stigma on schizophrenic patients (ISMI, Ritsher, 2003), along with Positive and Negative Syndrome Scale was used to evaluate the positive and negative symptoms in schizophrenic patients (Kay, et al., 1987), World Health Organization Quality of life BREF Scale (WHOQOL-BREF, 2003) was used to assess the quality of life of schizophrenic patients, along with another scale of Dysfunctional Attitude Scale (DAS, Weissman, 1978) was also used to assess the cognitive functioning of the schizophrenic patients. Studies showed that internalized stigma had significant positive correlation with dysfunctional attitude and negative significant correlation with symptoms and quality of life of schizophrenic patients. Internalized stigma had strong significant effects on the symptoms, quality of life and dysfunctional attitude. Studies also showed that people with mental illness has to face negative stereotype, rejection and finally alienation from society because of stigma which is a big hurdle in their process of recovery and treatment.
\end{abstract}

Keywords: Internalized Stigma; Schizophrenia; Quality of Life; Dysfunctional Attitude.

\section{Introduction}

Stigma is a social procedure described by restricting dismissal and accuse that outcomes as a matter of fact, observation or sensible desire of opposite social judgment around a man or a gathering (Weiss \& Ramakrishna, 2006). Internalized stigma is particularly associated with schizophrenia and has detrimental effects on them. Increased internalized stigma in schizophrenic patients results in discrimination, discernment which creates hurdle in their process of recovery and increased feeling of shame, guilt, hopelessness, demoralization, unemployment and poor quality of life (Cullen \& Shrout, 1989). Schizophrenia is a severe type of psychopathology which have severe negative effects on individual's academic, professional life. Because of stigma, schizophrenic patients cannot access to social support from their families to manage their illness and lead to social isolation, rejection and discrimination. Singular's mindfulness about their spot in life in the setting of their way of life and quality framework in relation to their goals, expectations, standard and concerns is called quality of life (Pak, Sci, 2014). Researches indicates that QOL is negatively correlated with internalized stigma. QOL in schizophrenic patient is quite impaired and lead to occupational dysfunction and delaying in recovery process.

Dysfunctional attitude are beliefs and negative subjective conventions about oneself, the world and the future (Beck, 1967). Patients with schizophrenia increases the chances of dysfunctional attitude. Individual with schizophrenia are more endorse negative belief about one self which results in diminished future probability of delight, acknowledgement, achievement and constrained psychological assets to perform an assignment.

This is association between internalized stigma, schizophrenia, its symptoms, quality of life and dysfunctional attitude and its mediating role in our research. Schizophrenia has a long history of negligence, demonization and suppression. Currently people are not aware of this illness and researchers do not get funding for this illness numbers of affective. Affected families also try to hide the illness from their families, friends and workplace associates, by lessening its influence on public awareness. University of Indiana proposed a study that mental illness has extensively attained acceptance by the public as treatable, but still people thought that individual who are suffering from schizophrenia are not suitable for keeping personal relationship and workplace success (link, et al., 1997; Jorm, et al., 1999 Because of stigma, people with schizophrenia cannot access to social support from their families to manage their illness but lead to feelings of social seclusion and solitude. The antagonistic significances of stigma prompts separation in lodging, instruction and business, and makes distress in individuals with schizophrenia (Link, et al., 1997; jorm, et al., 1999).

Schizophrenic patient's living conditions not only depend on people acceptance but also increase their severity of illness because of discrimination and stereotypes. Regardless of treatment advances, schizophrenic patient has to face a considerable stigma that confines their access to treatment and obstructs their active participation in society. Stigma hinders the mentally ill people from normal 
functioning and gain considerable place in society. Individuals with schizophrenia are largely stigmatized in our society. Relatives, close friends, people with mental illness and well-being professionals has to bear stigma (Link, et al., 1992). With the help of quality of life (QOL) one can describe the positive and negative aspects of the person's life in detail. Good physical functioning indicates good quality of life of a person. Many factors including anxiety, pain, lack of energy and depression can affect the quality of life (Bobs \& Portilla, 2014). There has been increasing interest in quality of life in schizophrenic patients in last two decades, where schizophrenia is consider as a severe, disabling, enduring disorder, with severe social and occupational dysfunction. The progression of atypical antipsychotics with wider efficiency and lower frequency of extrapyramidal side effects than typical neuroleptics has indorsed greater interest from the patient's viewpoint (Bobes \& Portilla, 2003). In Beck's cognitive theory, dysfunctional attitudes are implicit beliefs and constant dynamic rules that individual holds about himself and the world, are inflexible and impractical, that influence the subjective building of reality through an inaccurate information processing, simplistic character, arrange and develop only that stimuli which is reliable only with defined conviction, by ignoring unreliable information. The ultimate loss of entropy, or falsification of that outcome in depression possibilities nearly difficult to form self-worth, while mania for overemphasizing the positive and self-esteem rises (Beck, 1967). Stigma and Mental Health condition in Pakistan: The most appallingly ignored area in Pakistan, is mental health field which affects $10-16 \%$ of the population; with a large commonly of those affected being women. In a report of world health organization WHO, for 180 people only 400 psychiatrists and 5 psychiatric hospitals exist within the whole country. For half a million people only one psychiatrist is available and that is alarming figure in Pakistan.

\section{Methodology}

The population of the study was diagnosed (registered) 50 patients of Schizophrenia spectrum disorder and schizoaffective disorder with no comorbidity of any other disorder has been taken from Nishtar Hospital Psychiatry Department, Organization of fountain house rehabilitation Centre Lahore or Punjab Institute of Mental Health rehabilitation Centre Lahore from 25th November 2014 to 23rd April 2015. Calculated sample size was 50 patients who showed willingness to provide informed consent. Patient's age range was $18-64$ years among them $70 \%$ were male and $30 \%$ female. Research is based on purposive sampling is a form of nonprobability sampling which is based on the particular characteristic of the population of interest.

Table 2.1: Demographic Features of the Members $(\mathrm{N}=50)$

\begin{tabular}{lcc}
\hline Demographic Details & Frequency & Percentage \\
\hline \multicolumn{1}{c}{ Gender } & & \\
$\quad$ Male & 34 & $68 \%$ \\
$\quad$ Female & 16 & $32 \%$ \\
$\quad$ Age & & \\
18-33years & 21 & $42 \%$ \\
34-49years & 24 & $48 \%$ \\
$\quad$ 50-65years & 05 & $10 \%$ \\
\hline Education & & \\
Uneducated & 06 & $12 \%$ \\
Primary & 03 & $6 \%$ \\
Middle & 08 & $16 \%$ \\
Matric & 25 & $50 \%$ \\
F.A & 06 & $12 \%$ \\
B.A & 01 & $2 \%$ \\
M.A & 01 & $2 \%$ \\
Socioeconomic Status & & \\
Lower Class & 20 & $40 \%$ \\
Lower Middle Class & 15 & $30 \%$ \\
Middle Class & 14 & $28 \%$ \\
Upper Middle Class & 01 & $2 \%$ \\
Onset of Disorder & &
\end{tabular}

\begin{tabular}{lcc}
$16-26$ years & 21 & $42 \%$ \\
$27-37$ years & 19 & $38 \%$ \\
$38-48$ years & 07 & $14 \%$ \\
$49-59$ years & 03 & $6 \%$ \\
Course of Disease & & \\
Schizophrenic & 48 & $96 \%$ \\
Schizoaffective & 02 & $4 \%$ \\
Relapse if any & & \\
Yes & 08 & $16 \%$ \\
No & 42 & $84 \%$ \\
& & \\
\hline
\end{tabular}

Internalized Stigma of Mental Illness Scale (ISMI): The Internalized Stigma of Mental Illness (ISMI) scale is a 29-thing study measuring self-disrespect among persons with psychiatric issue, with subscale measuring Alienation, Stereotype Endorsement, Perceived Discrimination, Social Withdrawal, and disapproval resistance. ISMI had high inward consistency and test retest enduring quality. Each statement is assessed on the following 4point Likert scale: 1 = strongly disagree, $2=$ disagree, $3=$ agree, 4 = strongly agree. (Appendix C).

Positive and Negative Syndrome Scale (PANSS Rating Form): The Positive and Negative Syndrome Scale ( Appendix D) is a medicinal scale utilized for measuring side effect seriousness of patients with schizophrenia. It was distributed in 1987 by Stanley Kay, Lewis Opler, and Abraham Fiszbein. It is broadly utilized as a part of the investigation of antipsychotic treatment (Kay, et al., 1987). Scoring: As 1 rather than 0 is given as the slightest score for everything, a patient can't score lower than 30 for the total PANSS score. Scores are habitually given freely for the 7 positive things, 7 negative things, and 16 general psychopathology.it take $45 \mathrm{~min}$ to direct. In this study we used PANSS to gage schizophrenic positive, negative and general fanatical symptoms.

World Health Organization Quality of Life BREF (WHOQOLBREF): A wellbeing related instrument made by WHOQOL. It was decided to assess nature of wellbeing and life in patients of Schizophrenia Spectrum Disorder. (Orley \& Kuyken, 1994; WHOQOL Group 1994a, 1994b, Szabo, 1995, 1996). It is 26 things scale (Appendix E) and have four domains in which: Domain 1 is Physical wellbeing, Domain 2 is Psychological, Domain 3 is Social Relationships and Domain 4 is Environment. These things rate on 5 focuses, 1 of low score and up to 5 of high score for get an unpleasant score. By then changed score get by foul scores change. 4-20 is the degree of changed score. High score show amazing individual satisfaction of the people (WHOQOL, 1995).

Scoring: The WHOQOL-Bref does not have highlight scores, Mean substitutions are endorsed for Domain 1 Physical Health and Domain 4 Environment if near to one thing is coded missing Only three things need to be pivoted before scoring. The WHOQOL-Brief (Field Trial Version) makes a profile with four territory scores and two autonomously scored things around a solitary's general perspective of individual fulfillment and wellbeing. The four region scores are scaled in a constructive heading with higher scores exhibiting a higher individual fulfillment.

Dysfunctional Attitude Scale (DAS): The DAS is a 15-things instrument (Appendix F) that is expected to perceive and measure mental turns, particularly twists that may relate to or cause wretchedness. The things contained on the DAS are considering Beck's subjective treatment model and present 7 noteworthy worth structures: Approval, Love, Achievement, Perfectionism, Entitlement, Omnipotence, and Autonomy. (Weissman, 1978). Scoring: Any things that are missing, allocate a zero. To acquire the general score, essentially include the score all things (extending from 1 to 7). 1 = absolutely concur, $2=$ Agree all that much, $3=$ Agree marginally, $4=$ Neutral, $5=$ Disagree somewhat, $6=$ Disagree all that much, $7=$ thoroughly oppose this idea.

Completed questionnaire and measurements were entered into a computer data base. For analysis statistical package for social science (SPSS, 20.0) was used. Both descriptive and inferential statistics was applied in the analysis of the data. Descriptive statistics was utilized to measure mean, standard deviation, and alpha 
reliability. Pearson coefficient correlation was calculated to examine relationship between internalized stigma, dysfunctional attitude, symptoms and quality of life.

\section{Results}

In this study, researcher collected four standardized scales: Dysfunctional Attitude Scale (DAS), World Health Organization Quality of Life BREF (WHOQOL-BREF), Internalized Stigma of Mental Illness Scale (ISMI), Positive and Negative Syndrome Scale (PANSS Rating Form). Cronbach's alpha of scales administered in present research is given in table 3.1

Table 3.1: Cronbach's Alpha of Scales

\begin{tabular}{llcc}
\hline Sr. \# & \multicolumn{1}{c}{ Scales $\quad$ Cronbach's Alpha } & \multicolumn{2}{c}{ Items No } \\
1 & Dysfunctional Attitude Scale & .407 & 15 \\
2 & World Health Organization Quality of Life BREF .782 & 26 \\
3 & Internalized Stigma of Mental Illness Scale & .722 & 29 \\
4 & Positive and Negative Syndrome Scale & .970 & 30 \\
\hline
\end{tabular}

Table 3.2: Descriptive Statistics for the study variables

\begin{tabular}{lccccc}
\hline Variables M & SD & Minimum & \multicolumn{4}{l}{ Maximum Skewness } \\
\hline DAS & 3.61 & .529 & 1 & 4 & -.763 \\
QOL & & & & & \\
Physical Domain & 3.58 & .326 & 2 & 4 & -.284 \\
Psychological Domain & 3.34 .527 & 2 & 4 & -.407 \\
Social Domain & 3.38 .514 & 2 & 4 & -.591 \\
Environmental Domain 3.39 .484 & 1 & 4 & -1.237 \\
ISMI & 2.50 .162 & 2 & 2 & -.206 \\
Stigma Resistance & 2.32 & .261 & 2 & 3 & .925 \\
PANSS & & & & & \\
Positive symptoms & 2.79 & 1.51 & 1 & 6 & .859 \\
Negative Symptoms & 2.97 & 1.38 & 1 & 5 & .415 \\
General Symptoms & 2.54 & 1.14 & 1 & 6 & 1.36 \\
\hline
\end{tabular}

Table 3.2 showing descriptive statistics of study variables. Dysfunctional attitude scale has maximum mean value 3.61 and stigma resistance has minimum mean value 2.32. Skewness was also within range.

Table 3.3: Correlation Coefficient Matrix of Internalized Stigma, Dysfunctional Attitude, Symptoms and Quality of Life

\begin{tabular}{|c|c|c|c|c|c|c|c|c|c|c|}
\hline $\begin{array}{l}\text { S } \\
\text { r. } \\
\text { N } \\
\text { o. }\end{array}$ & $\begin{array}{l}\text { Varia- } \\
\text { ble }\end{array}$ & 1 & 2 & 3 & 4 & 5 & 6 & 7 & 8 & 9 \\
\hline 1 & ISMI & 1 & $\begin{array}{l}.36 \\
1 * *\end{array}$ & $\begin{array}{l}.78 \\
0^{* *}\end{array}$ & $\begin{array}{l}.87 \\
0^{* *}\end{array}$ & $\begin{array}{l}.86 \\
9^{* *}\end{array}$ & $\begin{array}{l}- \\
.44 \\
1 * *\end{array}$ & $\begin{array}{l}.51 \\
2^{* *}\end{array}$ & $\begin{array}{l}.2 \\
45\end{array}$ & $\begin{array}{l}.43 \\
8 * *\end{array}$ \\
\hline 2 & DAS & & 1 & $\begin{array}{l}- \\
.28 \\
7 *\end{array}$ & $\begin{array}{l}- \\
.34 \\
2 *\end{array}$ & $\begin{array}{l}- \\
.04 \\
9\end{array}$ & $\begin{array}{l}- \\
.16 \\
0\end{array}$ & $\begin{array}{l}- \\
.12 \\
4\end{array}$ & $\begin{array}{l}- \\
.1 \\
30\end{array}$ & $\begin{array}{l}- \\
.00 \\
4\end{array}$ \\
\hline 3 & $\begin{array}{l}\text { Positive } \\
\text { Symp- } \\
\text { toms }\end{array}$ & & & 1 & $\begin{array}{l}.63 \\
4 * *\end{array}$ & $\begin{array}{l}.57 \\
5 * *\end{array}$ & $\begin{array}{l}.33 \\
3^{*}\end{array}$ & $\begin{array}{l}.35 \\
2 * *\end{array}$ & $\begin{array}{l}.0 \\
80\end{array}$ & $\begin{array}{l}.24 \\
9\end{array}$ \\
\hline 4 & $\begin{array}{l}\text { Nega- } \\
\text { tive } \\
\text { Symp- } \\
\text { toms }\end{array}$ & & & & 1 & $\begin{array}{l}.70 \\
6 * *\end{array}$ & $\begin{array}{l}.27 \\
3\end{array}$ & $\begin{array}{l}.38 \\
7 * *\end{array}$ & $\begin{array}{l}.1 \\
14\end{array}$ & $\begin{array}{l}.25 \\
0\end{array}$ \\
\hline 5 & $\begin{array}{l}\text { General } \\
\text { Health }\end{array}$ & & & & & 1 & $\begin{array}{l}.38 \\
6^{* *}\end{array}$ & $\begin{array}{l}.49 \\
6 * *\end{array}$ & $\begin{array}{l}.2 \\
63\end{array}$ & $\begin{array}{l}.49 \\
1 * *\end{array}$ \\
\hline 6 & $\begin{array}{l}\text { Physi- } \\
\text { cal } \\
\text { Health }\end{array}$ & & & & & & 1 & $\begin{array}{l}304 \\
*\end{array}$ & $\begin{array}{l}.1 \\
93\end{array}$ & $\begin{array}{l}- \\
.70 \\
8^{* *}\end{array}$ \\
\hline 7 & $\begin{array}{l}\text { Psycho- } \\
\text { logical } \\
\text { Health }\end{array}$ & & & & & & & 1 & $\begin{array}{l}.2 \\
03\end{array}$ & $\begin{array}{l}.57 \\
6^{* *}\end{array}$ \\
\hline 8 & Social & & & & & & & & 1 & $\begin{array}{l}.33 \\
4^{*}\end{array}$ \\
\hline 9 & $\begin{array}{l}\text { En- } \\
\text { romen- } \\
\text { tal }\end{array}$ & & & & & & & & & 1 \\
\hline
\end{tabular}

*Correlation is significant at the 0.05 level, $* p<0.05$, (ISMI), internalized stigma of mental illness, (DAS), dysfunctional attitude scale, (QOL), quality of life.

Table 3.3 presents the relationship among internalized stigma, dysfunctional attitude, symptoms and quality of life. Internalized stigma was positively correlated with dysfunctional attitude scale $(\mathrm{r}=.361$,$) , internalized stigma was positively correlated with dys-$ functional attitude scale $(\mathrm{r}=.361$,$) , and negatively correlated with$ positive symptoms $(r=-.780)$, negative symptoms $(r=-.870)$, general symptoms ( $\mathrm{r}-\mathrm{-} .869)$, and with quality of life like physical domain $(r=-.441)$, psychological domain $(r=-.512)$, social domain $(\mathrm{r}-\mathrm{-} .245)$, and with environmental domain $(\mathrm{r}=-.438)$. Dysfunctional attitude was negatively correlated with positive symptoms $(\mathrm{r}=-.287)$ and with negative symptoms $(\mathrm{r}=-.342)$. Positive symptoms was positively correlated with negative symptoms $(\mathrm{r}=.634)$, and with general symptoms $(\mathrm{r}=.575)$. Negative symptoms was positively correlated with general symptoms $(\mathrm{r}=$ .706).

Physical domain of quality of life was positively correlated with psychological domain $(r=.304)$, and negatively correlated with environmental domain $(r=-.708)$. Psychological domain of quality of life scale was positively correlated with environmental domain $(\mathrm{r}=.576)$. Social domain was also positively correlated with environmental domain $(r=.334)$. Result findings indicates that there is positive significant correlation between internalized stigma and dysfunctional attitude but negatively significant correlation among symptoms and quality of life.

Table 3.4: Model 1 Linear Regression Analysis Showing Direct Effect of Internalized Stigma on Positive Symptoms of Schizophrenia $(\mathrm{N}=50)$

\begin{tabular}{llllll}
\hline Model & $\mathrm{b}$ & $\mathrm{SE}$ & $\mathrm{B}$ & $\mathrm{t}$ & $\mathrm{P}$ \\
\hline Constant & 125.859 & 12.341 & & 10.198 & .000 \\
ISMI & -1.738 & .201 & -.780 & -8.637 & .000 \\
\hline Note. $\mathrm{R}^{2}=$ & 608, Adjusted $\mathrm{R}^{2}=$ & . $000, \mathrm{~F}(74.604), \mathrm{P}<0.05$ &
\end{tabular}

Table 3.4 indicates the regression analysis for showing the effect of internalized stigma on positive symptoms of schizophrenia. Findings revealed that internalized stigma regressed upon positive symptoms. The $\mathrm{R}^{2}$ value is .608 that indicates that internalized stigma predicts the effects on positive symptoms $60.8 \%$.

Meditational Analysis of Dysfunctional Attitude

Table 3.5: Linear Regression Analysis Showing Effect of Internalized Stigma on Dysfunctional Attitude (Path A)

\begin{tabular}{llllll}
\hline Model & $\mathrm{B}$ & $\mathrm{SE}$ & $\mathrm{B}$ & $\mathrm{T}$ & $\mathrm{P}$ \\
\hline Constant & 16.976 & 13.943 & & 1.218 & .229 \\
ISMI & .610 & .227 & .361 & 2.683 & .010 \\
\hline
\end{tabular}

Note. $\mathrm{R}^{2}=.130$, Adjusted $\mathrm{R}^{2}=.112, \mathrm{~F}(7.201), \mathrm{P}<0.05$

Table 3.5 indicates the regression analysis for showing the effect of internalized stigma on dysfunctional attitude. Findings reveal that internalized stigma completely regressed upon dysfunctional attitude. The $\mathrm{R}^{2}$ value is .130 that indicates internalized stigma predicts the dysfunctional attitude $13.0 \%$.

Table 3.6: Linear Regression Analysis Showing Effect of Dysfunctional Attitude on Positive Symptoms (Path B)

\begin{tabular}{llllll}
\hline Model & $\mathrm{B}$ & $\mathrm{SE}$ & $\mathrm{B}$ & $\mathrm{t}$ & $\mathrm{P}$ \\
\hline Constant & 40.164 & 10.004 & & 4.015 & .000 \\
DAS & -.379 & .182 & -.287 & -2.080 & .043 \\
\hline Note. $\mathrm{R}^{2}=.083$, Adjusted $\mathrm{R}^{2}=064, \mathrm{~F}(4.324), \mathrm{P}<0.05$ &
\end{tabular}

Note. $\mathrm{R}^{2}=.083$, Adjusted $\mathrm{R}^{2}=.064, \mathrm{~F}(4.324), \mathrm{P}<0.05$

Table 3.6 indicates the regression analysis for showing the effect of dysfunctional attitude on positive symptoms. Findings reveal that dysfunctional attitude completely regressed upon positive symptoms. The $\mathrm{R}^{2}$ value is .083 it means dysfunctional attitude predicts the positive symptoms $8.3 \%$. 
Table 3.7: Sobel's Test for the Significance of Mediation

\begin{tabular}{llllll}
\hline & Regression & B & SE & $\begin{array}{l}\text { Sobel's } \\
\text { test }\end{array}$ & P \\
\hline Path A & $\begin{array}{l}\text { ISMI } \\
\text { predicting } \\
\text { DAS }\end{array}$ & .610 & .227 & & \\
& $\begin{array}{l}\text { DAS } \\
\text { predicting } \\
\text { positive } \\
\text { Pymptoms }\end{array}$ & -.379 & .182 & & \\
\hline
\end{tabular}

Note. $\mathrm{P}<0.05$ Where ISMI=internalized stigma of mental illness scale

$\mathrm{DAS}=$ dysfunctional attitude scale.

Table 3.7 indicate that the Sobel's $\mathrm{z}$ value is large $(\mathrm{p}<0.05)$. This indicates that the association between internalized stigma and positive symptoms have been highly significantly of the mediating variable.

Table 3.8: Linear Regression Analysis Showing Effect of Internalized Stigma on Dysfunctional Attitude (Path A)

\begin{tabular}{llllll}
\hline Model & $\mathrm{b}$ & $\mathrm{SE}$ & $\mathrm{B}$ & $\mathrm{t}$ & $\mathrm{P}$ \\
\hline Constant & 16.976 & 13.943 & & 1.218 & .229 \\
ISMI & .610 & .227 & .361 & 2.683 & .010 \\
\hline
\end{tabular}

Note. $\mathrm{R}^{2}=.130$, Adjusted $\mathrm{R}^{2}=.112, \mathrm{~F}(7.201), \mathrm{P}<0.05$

Table 3.8 indicates the regression analysis for showing the effect of internalized stigma on dysfunctional attitude. Findings reveal that internalized stigma completely regressed upon dysfunctional attitude. The $\mathrm{R}^{2}$ value is .130 that indicates internalized stigma predicts the dysfunctional attitude $13.0 \%$.

Table 3.9: Linear Regression Analysis Showing Effect of Dysfunctional Attitude on Negative Symptoms (Path B)

\begin{tabular}{llllll}
\hline Model & $\mathrm{b}$ & $\mathrm{SE}$ & $\mathrm{B}$ & $\mathrm{t}$ & $\mathrm{P}$ \\
\hline Constant & 43.205 & 8.972 & & 4.816 & .000 \\
PSPS & -.413 & .164 & -.342 & -2.524 & .015 \\
\hline
\end{tabular}

Note. $\mathrm{R}^{2}=.117$, Adjusted $\mathrm{R}^{2}=.099, \mathrm{~F}(6.371), \mathrm{P}<0.05$

Table 3.9 indicates the regression analysis for showing the effect of dysfunctional attitude on negative symptoms of schizophrenia. Findings reveal that dysfunctional attitude completely regressed upon negative symptoms. The $\mathrm{R}^{2}$ value is .117 it means dysfunctional attitude predicts the negative symptoms $11.7 \%$.

Table 3.10: Sobel's Test for the Significance of Mediation

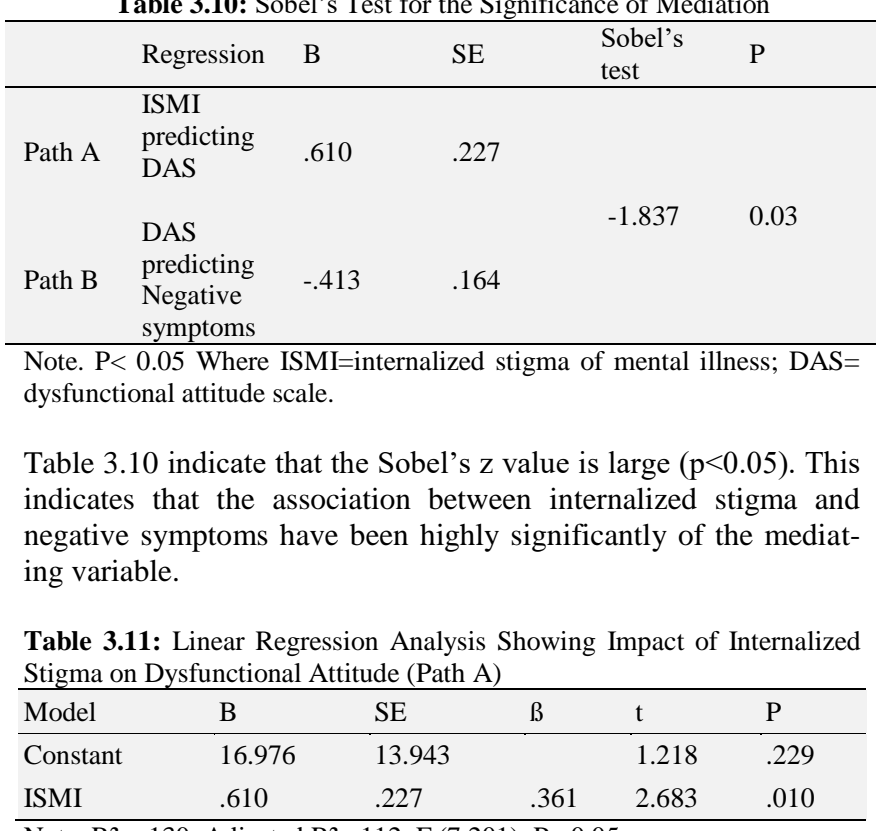

Note. $\mathrm{R}^{2}=.130$, Adjusted $\mathrm{R}^{2}=.112, \mathrm{~F}(7.201), \mathrm{P}<0.05$

Table 3.11 indicates the regression analysis for showing the effect of internalized stigma on dysfunctional attitude. Findings reveal that internalized stigma completely regressed upon dysfunctional attitude. The $\mathrm{R}^{2}$ value is .130 that indicates internalized stigma predicts the dysfunctional attitude $13.0 \%$.

Table 3.12: Linear Regression Analysis Showing Effect of Dysfunctional Attitude on QOL (Path B)

\begin{tabular}{llllll}
\hline Model & $\mathrm{b}$ & $\mathrm{SE}$ & $\mathrm{B}$ & $\mathrm{t}$ & $\mathrm{P}$ \\
\hline Constant & 95.010 & 8.710 & & 10.908 & .000 \\
DAS & -.105 & .159 & -.095 & -.660 & .512 \\
\hline
\end{tabular}

Note. $\mathrm{R}^{2}=.009$, Adjusted $\mathrm{R}^{2}=-.012, \mathrm{~F}(0.436), \mathrm{P}<0.05$

Table 3.12 indicates the regression analysis for showing no effect of dysfunctional attitude on quality of life of schizophrenic patients. Findings reveal that dysfunctional attitude not completely regressed upon QOL, The $\mathrm{R}^{2}$ value is .009 it means dysfunctional attitude do not predicts the quality of life $0.9 \%$.

Table 3.13: Sobel's Test for the Significance of Mediation

\begin{tabular}{llllll}
\hline & Regression & B & SE & $\begin{array}{l}\text { Sobel's } \\
\text { test }\end{array}$ & P \\
\hline \multirow{2}{*}{ Path A } & $\begin{array}{l}\text { ISMI } \\
\text { predicting } \\
\text { DAS }\end{array}$ & .610 & .227 & & \\
Path B & $\begin{array}{l}\text { DAS } \\
\text { predicting } \\
\text { QOL }\end{array}$ & -.105 & .159 & & \\
\hline
\end{tabular}

Note. $\mathrm{P}<0.05$ Where ISMI=Internalized stigma of mental illness; DAS= Dysfunctional attitude scale and QOL=Quality of life.

Table3.13 indicate that the Sobel's $\mathrm{z}$ value is smaller $(\mathrm{p}<0.05)$. This indicates that there is association between internalized stigma and quality of life but has no significant of the mediating variable.

\section{Discussion}

The most shameful neglected health field in Pakistan is mental illness. One of the most pertinent factor hindering mental healthcare within Pakistan is stigma. Within Pakistan it limits an individual from gaining complete social acceptance and proper treatment services. Since internalized stigma alludes to the procedure by which individual with emotional sickness apply negative generalizations to themselves, hope to be dismisses by others family and companions, and feel estranged from society. Individuals with maniacal issue (schizophrenia) are judged more brutally than individuals with melancholy or uneasiness issue. Internalized stigma is particularly associated with schizophrenia because patient with schizophrenia reluctant to go psychologist, psychiatrist and mental hospitals being labelled as insane or pagal. They more prefer to go to (peer, fakir, and babas) spiritual healers to avoid social stigma about mental illness, which results in severity of symptoms and difficulty in recovery process also decreasing their quality of life and lead to low hope for success and perception of inadequate intellectual possessions for retrieval chances.

The present study examine the relationship between internalized stigma and dysfunctional attitude, symptoms and quality of life in schizophrenic patients. In this study internalized stigma is positively correlated with dysfunctional attitude. This shows that the more self-reporting of internalized stigma the more person with schizophrenia had negative biased assumptions about oneself, surroundings and about his future. Increase dysfunctional attitude results in real depressive scenes which may incorporate side effects of tragic inclination, anhedonia, rest/wake, aggravations, weight change, and subjective changes. Dysfunctional attitude regarding accomplishment and preference play an important role in the process of recovery. On the off chance that one not discover future experience satisfying are identified with abnormal state of internalized stigma on the grounds that these maladaptive convictions and desire of disappointment in life in work lead to distance from family, peers, and withdrawn from society. 
In the line with past examination Ritsher, et al., 2003, internalized stigma was connected with despondency in our specimen, quality of life subscale satisfaction with family and satisfaction with social relations were furthermore related to internalized stigma, with poorer individual fulfillment in these spaces being joined with more unmistakable internalized stigma. Interestingly, internalized stigma was not related to objective subscales of personal satisfaction, for instance, family contact or social contact, demonstrating that internalized stigma accomplished more like the satisfaction with that contact. In this study results showed that internalized stigma is negatively correlated with quality of life in schizophrenic patients and also with its all subscales. This shows that high level of internalized stigma lead to poor quality of life. Lower quality of life lead to lower level at physical, psychological and environmental domain. Patients who have enough social support from their families along with proper antipsychotic drugs have higher rate of recovery and more positive and healthy life than those who do not have much social support and proper medication.

But in Pakistan the quality in females is very poor as compared to male because proper treatment facilities are not available female patients. Higher the internalized stigma lower the quality of life. Fewer side effect of antipsychotic drugs lead to better quality of life and patients who have better social support or involved community support programmed have good quality of life. Dysfunctional attitude is mediating the internalized stigma, symptoms and quality of life in schizophrenic patients. Results showed that dysfunctional attitude had strong mediational effect on the positive symptoms and negative symptoms of schizophrenia but had no relation or mediational effect on quality of life.

\section{Conclusion}

Current study discovered the mediating role of dysfunctional attitude between internalized stigma, positive and negative symptoms in schizophrenic patients but has no role in quality of life. Internalized stigma is positively correlated with dysfunctional attitude and negatively correlated with symptoms and quality of life. In Pakistan patients especially psychiatric patients has to face lots of problem because of stigma including internal and external discrimination limited access to employment and housing and proper treatment facilities. Therefore, individuals with mental illness are at a high danger of unemployment, disconnection, and deferred treatment-looking for, which regularly causes a genuine general wellbeing weight. Stigma is big hurdle in the way of treatment and recovery process in schizophrenic patients. Because patient seeks no treatment from psychiatrists and psychologist because of labelling and social stigma to mental illnesses. By reducing stigma especially internalized stigma we can improve the quality of life of schizophrenic patients and provide better health facilities.

We should learn and offer the actualities about psychological wellness and ailment become more acquainted with individuals encounters of maladjustment talk up in challenge when companions, family, associates or the media show false convictions and negative generalizations offer the same backing to individuals when they are physically or rationally unwell try not to mark or judge individuals with a dysfunctional behavior, approach them with deference and respect as you would any other individual try not to segregate regarding the matter of cooperation, lodging and occupation talk straightforwardly you could call your own experience of dysfunctional behavior. The more concealed dysfunctional behavior remains, the more individuals keep on accepting that it is dishonorable and needs to be hidden. In the finding of present study. It was concluded that patient with schizophrenia suffer more with internalized stigma than any other psychiatric disease. Internalized stigma has strong relationship with symptoms, quality of life and dysfunctional attitude of schizophrenic patients and there is significant mediating effect on internalized stigma, positive and negative symptoms and no effect on quality of life.

\section{References}

[1] Addington, D. MBBS, MRC Psych, FRCPC Professor Dept of Psychiatry Foothills Hospital 1403 - 29th Street NW Calgary, Alberta Canada T2N2T9 P: 403.944.4548 F: 403.270.3451.

[2] Alfred,T., \& Kamajian, (2010, November 11) "Schizophrenia Images and Pictures of Brains." Retrieved from http://www.schizophrenia.com/schizpictures.html.

[3] American Psychiatric Association. (2013, Oct 3). Diagnostic and statistical manual of mental Disorders: DSM-5. Washington, D.C: American Psychiatric Association.

[4] Awad, A.G, Voruganti, L.N.P, Heslegrave, R.J. (1997). A conceptual model of quality of life in Schizophrenia: description and preliminary clinical validation. Quality of Life Res, 6:21-26. http://dx.doi.org/10.1023/A:1026409326690.

[5] Bandura, A. (1989). Regulation of cognitive processes through perceived self-Efficacy. Developmental Psychology, 25,729 735. http://dx.doi.org/10.1037/0012-1649.25.5.729.

[6] Beck, A. T. (1967). Depression: Causes and treatment. Philadelphia: University of Pennsylvania Press.

[7] Beck, A. T., and wenzel, A., Riskind. (2006) Congnitive therapy and Research. Vol. 30,773-81.

[8] Bellack, A. S., Mueser, K. T., Morrison, R. L., Tierney, A., \& Podell, K. (1990). Remediation of Cognitive deficits in schizophrenia. American Journal of Psychiatry, 147,650-655.

[9] Benjamin \& Hankin (2004). Cognitive Therapy for Research.Vol 28 , 309 http://dx.doi.org/10.1023/B:COTR.0000031805.60529.0d

[10] Bobes, J., (2001) Current status of quality of life assessment in schizophrenic patients. Eur Arch Psychiatry Clin Neurosc. ; 251(suppl 2): 11/38-11/42. http://dx.doi.org/10.1007/bf03035125.

[11] Bobes, J., Garcia-Portilla, M.P. Quality of life in schizophrenia. In: Katschnig H, Freeman H, Sartorius N, eds. Quality of Life in Mental Disorders. Chichester, UK: John Wiley \& Sons Ltd; (2005), 153-168.

[12] Bordieri, J., Drehmer, D., (1986). Hiring decisions for disabled workers: Looking at the cause. Journal of Applied Social Psychology 16, 197-208. http://dx.doi.org/10.1111/j.15591816.1986.tb01135.x

[13] Buckley, P.F., Miller, B.J., Lehrer, D.S., \& Castle, D. J., (2009, March). "Psychiatric Comorbidities and schizophrenia". Schizophr Bull 35 (2): 383-402. http://dx.doi.org/10.1093/schbul/sbn135.

[14] Byrne, P. (2000). Stigma of mental illness and ways of diminishing it. Advances in Psychiatric Treatment, 6, 65-72. http://dx.doi.org/10.1192/apt.6.1.65.

[15] Corrigan, P.W., Calabress, J.D., (2005). Stratgies for assessing and diminishing self-stigma. In: Corrigan,P.W.( Ed), on the stigma of mental illness: Practical strategies for Research And social change, American Psychological Association, Washington, DC,pp.239-256. http://dx.doi.org/10.1037/10887-011.

[16] Eack. S. M., Newhill, CE, (2007), Psychiatric Symptoms and Quality of Life in Schizophrenia: A Meta-Analysis. Schizophrenia Bullettin, http://dx.doi.org/10.1093/schbul/sbl071.

[17] Ertugrul, A.M. D., Berna Uluğ, M. D., M. P. H. (2004, January). Social Psychiatry and Psychiatric Epidemiology, Volume 3.

[18] Goffman, E. (1963) Stigma: notes on the management of spoiled identity.New York: Prentice Hall, 3.

[19] Gorczynski, P., Faulkner, G. (2010). "Exercise therapy for schizophrenia". Cochrane Database of Systematic Reviews (5). http://dx.doi.org/10.1002/14651858.CD004412.pub2.

[20] Harrow, M., Jobe, T.H. (2013, March, 19). "Does long-term treatment of dchizophrenia with Antipsychotic medications facilitate recovery?" Schizophrenia bulletin 39.

[21] Heatherton, T. F., Kleck, R. E., Hebl, M. R., Hull, J. G. (2000). The Social Psychology of Stigma. Guilford Press.

[22] Hinshaw, S.P., Stier. A. (2008) Stigma as related to mental disorders. Annu Rev Clin Psychol. 4:367-93. http://dx.doi.org/10.1146/annurev.clinpsy.4.022007.141245.

[23] Hocking. B. (2003), the Second Australian National Survey of Psychosis Medical Journal of Australia, 27 June 2013.

[24] Hor, K., Taylor, M., (2010, November). "Suicide and schizophrenia: a systematic review of rates and risk factors". Journal of psychopharmacology, Oxford, England, 24 (4 Suppl): 81- 90. http://dx.doi.org/10.1177/1359786810385490.

[25] Jones, E., Farina, A. Hastorf , A., Markus, H., Miller, D., Scott, R. (1984) Social stigma: The Psychology of marked relationships, New York: Freeman, 
[26] Kay, S.R., Fiszbein, A., \& Opler, L.A. (1987). "The positive and negative syndrome scale (PANSS) for schizophrenia." (PDF). Schizophr Bull 13 (2): http://dx.doi.org/10.1093/schbul/13.2.261.

[27] Laursen, T.M., Munk-Olsen, T., Vestergaard, M. (2012, March) "Life expectancy and Cardio vascular mortality in persons with schizophrenia". Current opinion in Psychiatry 25 (2): 83-8. http://dx.doi.org/10.1097/YCO.0b013e32835035ca.

[28] Lehman, A.F. (1997), Instruments for measuring quality of life in mental illnesses. In Quality Of Life in Mental Disorders. Edited by: Katschnig, H., Freeman, H., Sartorius N. New York, NY: Wiley; 79-94

[29] Leucht, S., Tardy, M., Komossa, K., (2012, June). "Antipsychotic drugs versus placebo for Relapse prevention in schizophrenia: a systematic review and meta-analysis". Lancet 379 (9831): 2063-71 http://dx.doi.org/10.1016/S0140-6736(12)60239-6.

[30] Luckstead, A., Drapalski, A., Calmes, C., Forbes, C., DeForge, B. \& Boyd, J. (2011). Ending Self-Stigma: Pilot Evaluation of a New Intervention to Reduce Internalized Stigma among People with Mental Illness. Psychiatric Rehabilitation Journa,1 35 (1), 51- 54. http://dx.doi.org/10.2975/35.1.2011.51.54.

[31] Mahmood .A, (2014, September 20).' Mental illness in Pakistan The toll of neglect, 'The Dawn, Retrieved from http://www.DAWN.com

[32] Makara, M., Studzinska, Wolynaik, M., \&Partyka, I. (2010) Journal of Pre-clininca Reasearch volume 5 .

[33] Mark, L., Hatzenbuehler, \& Katie, A. McLaughlin. (2013) society of behavioral medicine,

[34] Marshall, M., Rathbone, J. (2011, Jun 15). "Early intervention for psychosis". The Cochrane Database of systematic reviews. http://dx.doi.org/10.1002/14651858.CD004718.pub3.

[35] Parson, R. D., Stephanie, Lewis, H. \& Deborah, S (2001).Educational Psychology: A Practitioner- Researcher Model of Teaching. Singapore: Thomson Learning Inc.

[36] Paul, H. L., Jenifer, L. Vohs. J. (2009) vol 1127. http://dx.doi.org/10.12669/pjms.305.5239.

[37] Paul, H. Lysker, Louanne W. Davis, Debbie, M., Warman, A., Nicole, B. (2007) Volume 149.

[38] Picchioni, M. M., \& Murray, R. M. (2007, July). "Schizophrenia". BMJ 335 (7610): 91-5. Putman, S. (2008) Mental illness: diagnostic title or derogatory term? Attitudes towards mental illness. Developing learning resources for use within a clinical call centre. A systematic literature review on attitudes towards mental illness. J Psychiatry Mental Health Nurs: 15(8):684-93

[39] Picchioni, M. M., Murray, R.M. (2007, July). "Schizophrenia". BMJ 335 (7610): 91-5 Pak J Med Sci 2014; 30(5):1123

[40] Ritsher (Boyd), J., Otilingam, P.G., Grajales, M. (2003) Internalized stigma of mental illness: Psychometric properties of a new measure. Psychiatry Res 121: 31-49. http://dx.doi.org/10.1016/j.psychres.2003.08.008.

[41] Ritsher, B. J., Otilingam, P. G., \& Crajales, M. (2003). Internalized Stigma of Mental Illness: Psychometric Properties of a New Measure. Psychiatry Research. 121, 31-49. http://dx.doi.org/10.1016/j.psychres.2003.08.008.

[42] Rosenfield S: (1997) Labeling mental illness. The effects of received services and perceived Stigma on life satisfaction.Am Sociol Rev, 62:660-672. http://dx.doi.org/10.2307/2657432.

[43] Saifi, S., \& Mehmood, T. (2011). Effects of socio-economic status on student achievement. International Journal of Social Sciences and Education, 1(2), 119-128.

[44] Sartorius N. (1997) Fighting schizophrenia and its stigma: A new World Psychiatric Association educational programme.Br J Psychiatry, 170:297. http://dx.doi.org/10.1192/bjp.170.4.297.

[45] Sibitz, I., Friedrich, M.E., Unger, A., Bachmann, A., Benesch, T., Amering, M. \& Psychiatr, P. (2013, Mar) 40(2):83-91. Epub 2013 Jan 25. German.

[46] Skevington, S.M., Lotfy, M., O'Connel, K. A., WHOQOL Group (2004). The World Health Organization's WHOQOL-BREF quality of life assessment: psychometric properties and results of the international field trial. A report from the WHOQOL group. Quality of Life Research, 13(2), 299-310. http://dx.doi.org/10.1023/b:qure.0000018486.91360.00.

[47] Stafford, M.R., Jackson, H., Mayo-Wilson, E., Morrison, A.P., Kendall, T. (2013, January 18) "Early interventions to prevent psychosis: systematic review and meta-analysis". BMJ (Clinical research Ed.) 346. http://dx.doi.org/10.1136/bmj.f185.

[48] Tandon, R., Keshavan, M.S., Nasrallah, H. A. (March, 2008). "Schizophrenia, "Just the Facts": what we know in 2008 part 1: overview". Schizophrenia Research 100 (1-3):.01.022. PMID
[49] The WHOQOL Group. (1995) the World Health Organization Quality of Life Assessment (the WHOQOL): position paper from the World Health Organization. Soc Sci Med.; 41:1403-1409. http://dx.doi.org/10.1016/0277-9536(95)00112-K.

[50] Van Os, J., Kapur, S. (2009, August). "Schizophrenia". Lancet 374 (9690): 635-45. http://dx.doi.org/10.1016/S0140-6736(09)60995-8.

[51] Weissman, A. (1978). The dysfunctional attitudes scale: A validation study. Philadelphia: University of Pennsylvania.

[52] Weissman, A. N. \& Beck, A. T. (1978). Development and validation of the Dysfunctional Attitudes Scale: a preliminary investigation. In: Proceedings of the meeting of the American Educational Research Association. Toronto,

[53] Ying LU, Xiaoping WANG. (2012) Shanghai Archives of Psychiatry, Vol.24, No.2. 